Review

\title{
The role of WT1 in breast cancer: clinical implications, biological effects and molecular mechanism
}

\author{
Ye Zhang ${ }^{*}$, Wen-Ting Yan ${ }^{1 *}$, Ze-Yu Yang2 ${ }^{*}$, Yan-Ling Li ${ }^{1}$, Xuan-Ni Tan ${ }^{1}$, Jun Jiang1, Yi Zhang ${ }^{1}$, Xiao-Wei \\ $\mathrm{Qi}^{1}{ }^{凶}$ \\ 1. Breast and Thyroid Surgery, Southwest Hospital, Army Medical University, Chongqing 400038, China \\ 2. Breast and Thyroid Surgery, Chongqing General Hospital, University of Chinese Academy of Sciences, Chongqing 400013, China \\ ${ }^{*}$ Contributed equally \\ $\square$ Corresponding author: Dr. Xiao-Wei Qi, Breast and Thyroid Surgery, Southwest Hospital, Army Medical University, Gaotanyan Street 29, Chongqing 400038, \\ China. Tel.: 86-23-68754160, Fax.: 86-23-68754160, E-mail: qxw9908@foxmail.com
}

(C) The author(s). This is an open access article distributed under the terms of the Creative Commons Attribution License (https://creativecommons.org/licenses/by/4.0/). See http://ivyspring.com/terms for full terms and conditions.

Received: 2019.09.03; Accepted: 2020.01.22; Published: 2020.02.24

\begin{abstract}
Although Wilms' tumor gene 1 (WT1) was first cloned and identified as a tumor suppressor gene in nephroblastoma, subsequent studies have demonstrated that it can also play an oncogenic role in leukemia and various solid tumors. WT1 exerts biological functions with high tissue- and cell-specificity. This article reviews the relationship between WT1 and breast cancer from two aspects: (1) clinical application of WT1, including the relationship between expression of WT1 and prognosis of breast cancer patients, and its effectiveness as a target for comprehensive therapy of breast cancer; (2) the biological effects and molecular mechanisms of WT1 in the development and progression of breast cancer, including proliferation, apoptosis, invasion, and metastasis of breast cancer cells.
\end{abstract}

Key words: WT1, breast neoplasms, prognosis, carcinogenesis

\section{Introduction}

Malignant tumor is the second most common cause of death worldwide. There are estimated 18.1 million new cases of malignant tumors and 9.6 million malignant tumor-related deaths in 2018 [1]. In China, the incidence of malignant tumor is about 200/100,000, with an increasing trend, and deaths caused by malignant tumors account for nearly $20 \%$ of total deaths [2]. The biological events such as occurrence, invasion, and metastasis of malignant tumors are regulated at multiple levels and by various factors. One of the key factors is the imbalance between oncogenes and tumor suppressor genes. It is necessary to explore new functions of existing oncogenes or tumor suppressor genes in order to clarify the mechanism of malignant tumor occurrence and progression, which then will benefit to find effective diagnostic and therapeutic targets [3].

Wilms' tumor 1 (WT1) was originally cloned and identified as a tumor suppressor gene in Wilms tumors [4]. Then, further studies have shown that
WT1 can regulate a series of target genes and signaling pathways in the formation of organs such as the heart, kidney, spleen, and retina [5-9]. Moreover, the wild-type WT1 was detected in leukemia and solid tumors, suggesting its role as an oncogene $[10,11]$. This article focuses on the relationship between WT1 and breast cancer to comprehensively understand the effects and the underlying mechanisms of WT1 in breast cancer.

\section{Structure of WT1 gene, mRNA, and protein}

WT1 was originally identified as a tumor suppressor gene in nephroblastoma, and was inactivated in tumors. The population with WT1 gene mutation was more susceptible to nephroblastoma [4, 12]. WT1 is located on short band 1 region 3 of human chromosome 11 and is about $50 \mathrm{~kb}$ in length with 10 exons, and is rich in GC homologous sequences [13]. WT1 has two splice sites: a 51-bp long one between 
the exon 5 zinc finger structure and the glutamic/ proline amino acid (AA)-rich region encodes $17 \mathrm{AA}$; a 9-bp long one between the third and fourth zinc finger structures at the end of the exon 9 encodes three AA (lysine-threonine-serine, KTS) (Figure 1). The splicing at two sites of WT1 mRNA could produce four major isoforms: WT1 A (17AA-/KTS-), WT1 B (17AA-/ KTS+), WT1 C (17AA+/KTS-), and WT1 D (17AA+/ KTS+) [13-17]. Since no physiological function of WT1 $\mathrm{C}$ has been reported in literature, it was removed from the National Center for Biotechnology Information (NCBI) Entrez Gene database in April 2011, and another two isomers WT1 E and WT1 F were added. The corresponding RefSeq NM (mRNA) and NP (protein) numbers for WT1 A, WT1 B, WT1 D, WT1 E, and WT1 $F$ are as follow: NM_000378.4 $\rightarrow \mathrm{NP}_{-}$ 000369.3, NM_024424.3 $\rightarrow$ NP_077742.2, NM_024426.4 $\rightarrow$ NP_077744.3, NM_001198551.1 $\rightarrow$ NP_001185480.1, and NM_001198552.1 $\rightarrow$ NP_001185481.1, respectively [18].

The full length product encoded by WT1 is a 5254-kD protein. The C-terminal consists of four zinc finger structures, each of which has two cysteines and two histidines. The zinc finger domain is associated with DNA binding, regulating gene transcription. Proline, glutamic acid, serine, and glycine are abundant in the N-terminal, and it can interact with DNA and RNA and participate in protein interaction. KTS insertion or deletion can alter the specific combination of WT1 protein and DNA, and the WT1 (KTS-) isomer acts as a transcription factor [13-17].

\section{Significance of WT1 in embryogenesis}

During embryogenesis, WT1 participates in the formation of organs such as the heart, kidney, spleen, and retina by regulating multiple target genes and signaling pathways [5-9]. The low expression of WT1 is observed in normal tissues because of limited expression sites, while only microexpression of WT1 is reported in glomerular podocytes, granulosa cells, the endometrium, testicular cells, and immature hematopoietic cells in the spleen and bone marrow $[5,6,19$, 20]. This indicates that WT1 expression is cell- and tissue-specific.

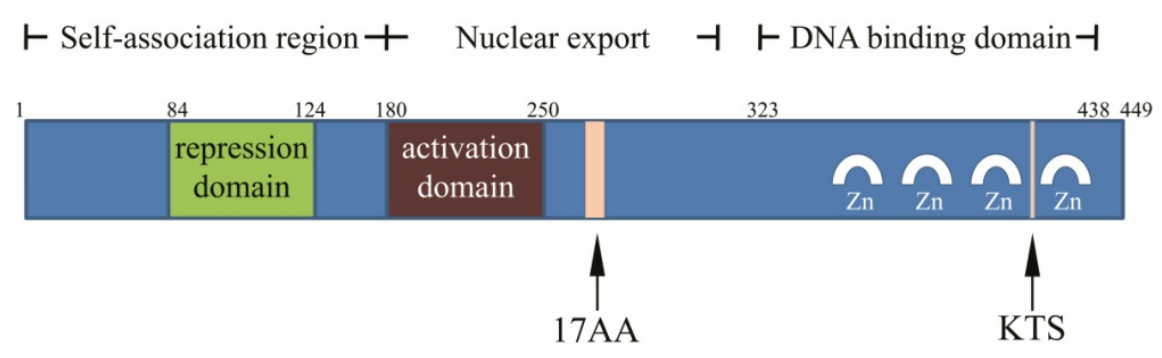

Figure 1. Structure of WT1 protein.
During embryonic development, WT1 affects the transcriptional expression of genes by regulating the promoter activity of various growth factors and their receptors. The known target sequence of WT1 is 5'-GCGGGGGCG-3', and the target genes including insulin-like growth factors (IGFs) and their receptor (IGF1R), platelet-derived growth factor A (PDGFA), epidermal growth factor (EGF), transforming growth factor beta (TGF- $\beta$ ), macrophage colony-stimulating factor (M-CSF), multidrug resistance 1 (MDR1), Bcl-2, c-MYC, human telomerase reverse transcriptase (hTERT), and cyclin E. WT1 protein can also bind to GC-rich homologous sequence of WT1 gene to regulate its own expression. The effect of WT1 on its target genes (activation or inhibition of transcription) is highly cell- and tissue-specific, and is also affected by isomers and interactions with other genes [10, 11, 13-17]. Martínez-Estrada et al.[21] found that WT1 can participate in embryonic heart development by inducing epithelial-mesenchymal transition (EMT). Knockout of WT1 could reduced the number of mesenchymal progenitor cells and inhibited cell differentiation, upregulating E-cadherin and downregulating $\mathrm{N}$-cadherin, alpha smooth muscle actin, and Snail. WT1 can inhibit E-cadherin (CDH1) transcription and promote SNAIL transcription by binding to their promoters. Kirschner et al. [22] revealed that WT1 can transcribe vascular genes, such as cadherin 5 (CDH5, vascular cadherin), vascular endothelial growth factor and angiopoietin, and activate their expression. Based on these findings, it is concluded that WT1 can promote the transcription of vascular endothelial genes and participate in blood vessel.

\section{Role of WT1 in breast cancer}

As mentioned above, with the research progressed, the function of WT1 beyond as a tumor suppressor factor has been reported. Therefore, it is generally believed that WT1 is inactivated by point mutation or deletion so as to trigger malignant tumor. WT1 inactivation results in the loss of specific target gene binding, interfering with normal regulation of transcription, cell growth, differentiation, and proliferation, and eventually leads to tumorgenesis. However, it is also found that WT1 can be detected in various tumors, and mutation analysis has suggested that WT1 rarely mutates, indicating that WT1 could also function as an oncogene. WT1 may promote cell proliferation and participate in tumor cell infiltration and metastasis by regulating the transcriptional expression of growth factor genes. 
Recent findings provide new evidence for the oncogene function of WT1 [23, 24]. Harkamp et al. [23] suggested that the HtrA2 (HtrA serine peptidase 2) is the binding partner of WT1. Inhibiting HtrA2 activity can block WT1 proteolysis, suggesting that HtrA2/ OMI can degrade WT1. Under apoptosis-inducing conditions, HtrA2/OMI-dependent WT1 proteolysis leads to the loss of regulation of the downstream target genes of WT1 and increased apoptosis. Vicent et al [25] found that RNA interference (RNAi) of WT1 significantly reduced tumor burden, induced cell senescence, and inhibited tumor cell proliferation in a proto-oncogene KRAS-induced tumor model. WT1 also affects cytoskeletal rearrangement and participates in cell movement by regulating actin activity, which indicated the possible role of WT1 in cancer cell invasion and migration [26].

\section{WTI expression in breast cancer}

In 1997, Silberstein et al [27] immunohistochemically analyzed invasive breast cancer tissues from 21 patients and found that WT1 was expressed in normal breast ducts and lobules, but scarce in breast cancer cells. Based on the aforementioned results, WT1 was regarded as a tumor suppressor gene in breast cancer. In 1999, Loeb et al [28] used reverse transcription (RT)-PCR to detect the expression of WT1 mRNA in breast cancer tissues of 31 cases, and found that WT1 expression was high in primary breast cancer $(27 / 31)$ and low in normal breast tissue $(1 / 20)$, suggesting that WT1 may act as an oncogene. Oji et al [29] sequenced the DNA of 36 breast cancer tissues and confirmed that the WT1 detected in the above breast cancer samples was not mutated. Therefore, the results confirm that wild-type WT1 acts as an oncogene in breast cancer. Furthermore, Provenzano et al. [30] compared the expression of 6 proteins in 266 non-small cell lung cancer samples and 837 primary breast cancer samples, and results showed that cytoplasmic staining for WT1 favoured breast origin. In addition, Craig et al. [31] detected focal amplifications of WT1 in triple-negative breast cancer (TNBC). We have previously demonstrated that single-nucleotide polymorphisms (SNPs) of WT1 can decrease WT1 mRNA expression and are associated with reduced breast cancer risk [32]. Recently, a histopathological study confirmed that WT1 protein expression is higher in breast tumor than in tumor-free tissue [33].

\section{Relationship between WTI and prognosis in breast cancer}

Miyoshi et al. [34] detected the expression of WT1 mRNA in 99 breast cancer cases. The results suggested that WT1 expression was not associated with patients' clinicopathological parameters, but patients with high WT1 expression had significantly lower overall survival (OS) than patients with low WT1 expression. Besides, multivariate analysis showed that WT1 was an independent indicator of poor prognosis for breast cancer patients. We found that high WT1 mRNA expression was associated with high histological grade, estrogen receptor (ER)negative status, basal-like subtype, and ERBB2 (erb-b2 receptor tyrosine kinase 2, HER2) subtype in breast cancer patients. Patients with high WT1 expression had a shorter disease-free survival (DFS) than patients with low WT1 expression [35]. Choi et al. [36] performed an immunohistochemical analysis of 100 invasive ductal breast cancer cases and showed that WT1 expression was closely related to tumor grading and DFS. Patients with positive WT1 expression had significantly longer DFS than patients with negative WT1 expression. Our meta-analysis showed that WT1 expression are not significantly related to OS and DFS of breast cancer patients, and the variance among studies may be due to different detection methods and antibody inconsistency [37].

\section{Relationship between WTI and its potential application in breast cancer}

Higgins et al. [38] studied the safety and efficacy of WT1 immunotherapy in combination with standard neoadjuvant therapy in patients with positive WT1 expression. This immunotherapy induces $\mathrm{T}$ cell recognition of tumor antigens by vaccination, and activates the immune response to produce tumor antibodies. Results showed patients treated by aromatase inhibitors were well tolerated to concurrent therapy and more likely to produce WT1-specific antibodies, whereas patients who received neoadjuvant chemotherapy or trastuzumab had relatively less WT1-specific antibodies. In another study, WT1 peptide-pulsed DC vaccination was used to treat advanced cancer patients. Results showed that all the four patients with advanced breast cancer achieved clinical response [39]. Li et al [40] suggested that the WT1 SNP rs1799937 is associated with pathological complete response (pCR) after anthracycline and/or taxane based neoadjuvant chemotherapy and that patients with the TT genotype are more likely to achieve pCR. In addition, Wu et al. [41] reported that among 389,795 WT1 SNPs associated with pCR, rs6044100 and rs1799937 were significantly associated with $\mathrm{pCR}$ after neoadjuvant chemotherapy, suggesting that WT1 may be a potential target in breast cancer. 


\section{WTI and breast cancer cell proliferation and apoptosis}

In 2002, Zapata-Benavides et al. [42] found that stimulating breast cancer cell proliferation with $17 \beta$-estradiol significantly increased WT1 protein expression, while, tamoxifen or all-trans retinoic acid could inhibit cell proliferation. Moreover, interfering with WT1 expression inhibited cell proliferation and decreased cyclin D1 expression. Caldon et al. [43] also reported that interfering with WT1 expression decreased the proportion of cells in S phase, leading to cell proliferation arrest, differentiation, and apoptosis, which may be related to decreased expression of cyclin D1. Nasomyon et al. [44] found WT1 induced estrogen-independent growth and anti-estrogen resistance in MCF7 cells through enhanced expression of EGFR and HER2. Navakanit et al. [45] found that silencing WT1 could inhibit the growth of MCF-7 cell line. In addition, Tuna et al. [46] found that HER2 could upregulate WT1 expression through the Akt signaling pathway, promoting breast cancer cell proliferation and inhibiting apoptosis, suggesting that WT1 can promote breast cancer cell proliferation. As HER2 plays an important role in the stemness maintain of breast cancer stem cells, WT1 may play a role in maintaining the biological characteristics of breast cancer stem cells.

WT1 can increase the malignancy of breast cancer, leading to poor prognosis in patients with high WT1 expression. Han et al. [47] reported that WT1 overexpression antagonized tamoxifen-induced apoptosis in MCF-7 cells, and further studies showed that WT1 could bind to the ERa promoter and inhibit its transcriptional activity, which finally led to ERa downregulation and caused estrogen resistance. Furthermore, Wang et al. [48] found that WT1-upregulated EGFR (epidermal growth factor receptor, HER-1) expression was associated with endocrine therapy resistance in breast cancer.

The major WT1 subtypes have inhibitory functions, e.g., WT1 (17AA+/KTS+), WT1 (17AA+/ KTS-), and WT1 (17AA-/KTS+) can inhibit caspase-3, caspase-9, and Bax expression to play an anti-apoptotic role [49]. Graidist et al. [50] found that the expression of two short WT1 subtypes, i.e., T-KTS+ and T-KTS-, and two major subtypes, i.e., WT1 (17AA+/KTS+) and WT1 (17AA+/KTS-), can inhibit the expression of the apoptotic genes such as p53, Bak, and caspase-7 in MCF-7 cells, inhibiting doxorubicin-induced cell death. Navakanit et al. [45] found that after RNAi downregulated WT1 in MCF-7 cells, doxorubicin toxicity was significantly increased, causing increased apoptosis of cells deaths.

Much of the current research supports the premise that WT1 plays an oncogenic role in breast cancer, promoting cell proliferation and inhibiting apoptosis, but some other studies have different findings. For example, Zhang et al. [51] reported that WT1 inhibited breast cancer cell growth by regulating the stability of $\beta$-catenin. Reizner et al. [52] found that WT1 interacted with ERa and blocked the transactivation of ERa to the IGF-1R, resulting in the inhibition of IGF1R transcription and decreased cell proliferation. Wang et al. [53] showed that WT1 inhibited the malignant transformation of the MCF10A normal breast cell line and its tumorigenic ability in nude mice. Burwell et al. [54] transduced the WT1 (exon 5 [Ex5]-/KTS-) and WT1 (Ex5+/KTS+) isoforms into $\mathrm{H} 16 \mathrm{~N} 2$ cells and found that WT1 (Ex5-/KTS-) increased p21 expression and cell proliferation with declining reproductive ability and G2 arrest. However, WT1 (Ex5+/KTS+) did not affect p21 expression, but promoted EMT, which was demonstrated by membrane E-cadherin translocation into the nucleus, and cells developing mesenchymal cell-like morphology. The study by Wang et al [53] showed that high WT1 expression inhibited MCF10AT3B cell growth and inhibited their tumorigenic ability in nude mice. Jomgeow et al. [55] found that WT1 (17AA-/KTS-) expression induced three-dimensional morphological changes in the ZR-75 and SK-BR-3 breast cancer cell lines, and significantly reduced the sizes of both cell types. These results suggest a complex role of WT1, which differs between cell types and even in different subgroups of similar cells. WT1 has multiple isomers, and their function depends on the ratios and roles, which should be further clarified. Recently, Lee et al. [56] found that cugWT1 (WT1 translated from a CUG site) and augWT1 (WT1 translated from an AUG site) have different effect in breast cancer because they have different promoters of protein synthesis. cugWT1 is highly expressed in breast cancer cells, which can mediate tumor cell transformation and up-regulate c-MYC, BCL2, and EGFR expression; silencing it leads to decreased anchorage-independent growth and proliferation of breast cancer cells. augWT1 usually functions as a tumor suppressor gene, and cugWT1 overexpression inhibits tumor cell colony formation and inhibits expression of the above genes by recruiting histone deacetylase (HDAC1).

\section{WTI and breast cancer cell invasion and migration}

Zhang et al. [57] found that WT1 is involved in breast cancer cell migration mediated by focal adhesion kinase and keratinocyte growth factor (KGF). Artibani et al. [58] reported that knocking out WT1 in the TNBC MDA-MB-157 cell line significantly increased cell movement, invasion, and metastasis, 
but had no effect on cell proliferation and apoptosis, and tumor stem cell characteristics. Bissanum et al. [59] suggested that, in TNBC, WT1 B and WT1 C upregulate EphA2 (EPH receptor A2) expression, activate $\beta$-catenin signaling transduction, and promote vimentin expression, enhancing cell migration and promoting the formation of vasculogenic mimicry. Our study showed that TGF- $\beta$ could upregulate WT1 in breast cancer cells, altering cell epithelial morphology to mesenchymal morphology and promoting the proliferation, invasion, and migration of cancer cells significantly [60].

\section{Regulatory factors of the WTI gene in breast cancer cells}

As a transcription factor, WT1 can widely regulate a variety of target genes [61]. Chesor et al. [62] found that silencing WT1 in MDA-MB-468 cells significantly inhibited the expression of PDGF receptor alpha (PDGFRA, involved in cell proliferation) and guanine nucleotides exchange factor 1, which is involved in migration. Keating et al. [63] believed that WT1 is a tumor suppressor gene and can reduce thromboxane receptor a expression by inhibiting its transcription.

At present, there are few studies on the upstream regulatory factors of WT1 expression. Tuna et al. [64] found that IGF1 increased WT1 protein expression in a time-dependent manner through the Akt pathway in MCF-7 cells. In addition, the HER2/neu gene regulated WT1 protein expression through Akt [46]. Xie et al. [65] found that WT1 was highly expressed in breast cancer tissues and microRNA-193a could inhibit its expression by binding to the WT1 coding region. MicroRNA-193a expression in breast cancer was negatively correlated with WT1 expression, and overexpression of WT1 could partially offset the activity of microRNA-193a. Cheng et al. [66] reported that WT1, a transcriptional inhibitor of STIM1 (stromal interaction molecule 1), was upregulated after TGF- $\beta$ treatment in MDA-MB-231 cells, and WT1 knockdown partially reversed the STIM1 downregulation caused by TGF- $\beta$. Our previous study showed that TGF- $\beta$ can induce EMT by upregulating WT1 breast cancer cells, resulting in promoting proliferation, invasion, and migration of tumor cells [60].

Oncogene effect

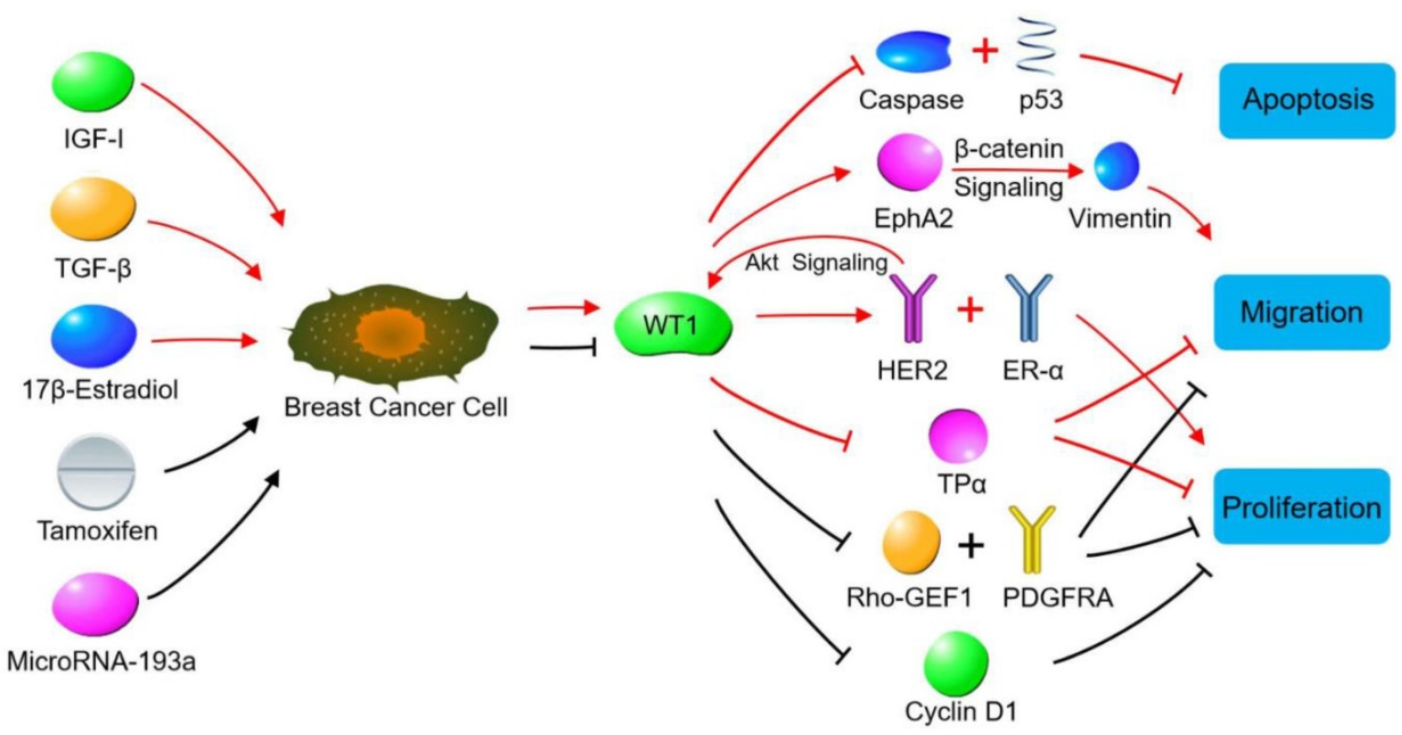

Tumor suppressor gene effect

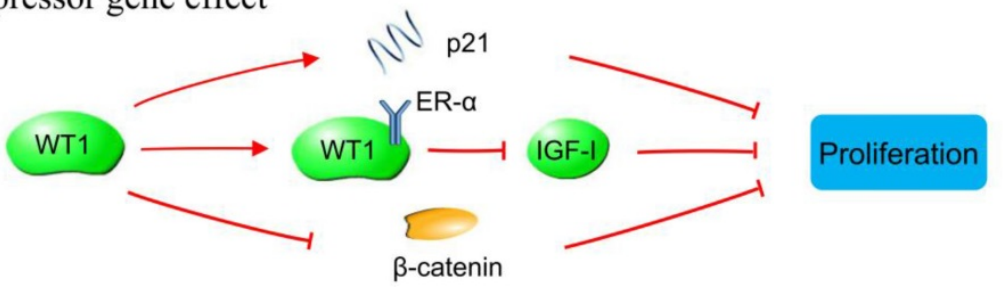

Figure 2. WT1 plays a role in promoting or suppressing cancer cells through various signaling pathways in breast cancer. Oncogene effect: Red lines indicate signaling pathways initiated by increasing WT1 expression. The WT1 expression is up-regulated by IGF-1, TGF- $\beta$ and $17 \beta$-estradiol in breast cancer cells. The up-regulated WT1 can regulate the proliferation, migration, and apoptosis of breast cancer cells by acting on molecules or signaling pathways such as Caspase family, p53, EphA2, HER2, ER- $\alpha$, and TPa. Black lines indicate the biological effects produced by inhibiting WT1 expression. Tamoxifen and MicroRNA-93a inhibit the expression of WT1 in breast cancer cells, so that the expression of Rho-GEF1, PDGFRA and cyclin D1 is inhibited, leading to the suppressed proliferation of breast cancer cells. Tumor suppressor gene effect: WT1 inhibits breast cancer cells by binding to ER- $\alpha$, or promoting $\mathrm{P} 21$ expression, or inhibiting $\beta$-catenin. 


\section{Conclusion}

WT1 and its encoded protein are highly expressed in hematological malignancies and solid tumors such as breast cancer, lung cancer, pancreatic cancer, and prostate cancer. In addition, patients with WT1 gene amplification could produce antibodies against WT1 protein and cytotoxic T lymphocytes, indicating that WT1 protein is highly immunogenic and could serve as a therapeutic target. Currently, WT1 vaccines against leukemia, breast cancer, lung cancer, and pancreatic cancer are undergoing phase I or II clinical trials, and their efficacy and adverse reactions are also being under investigation. It is important to determine whether WT1 plays a significant role in the invasion, migration, and metastasis of breast cancer and explore its molecular mechanism. Clinical application of WT1for the treatment of breast cancer still needs to be investigated by more well-designed clinical trials.

\section{Acknowledgment}

This study was supported by grants from the National Natural Science Foundation of China (No. 81102030), Biotechnology Innovation Program of Southwest Hospital (No. SWH2016JCYB-39), Talents Training Program of Third Military Medical University (No. 2017MPRC-18), Chongqing Basic Research and Frontier Exploration Project (No. cstc2018jcyj A0137) and Military Medical Staff Innovation Plan of Southwest Hospital (No. SWH2018BJLC-04) as well as Army Medical University (No. XZ-2019-505-042).

\section{Competing Interests}

The authors have declared that no competing interest exists.

\section{References}

[1] Bray F, Ferlay J, Soerjomataram I, Siegel RL, Torre LA and Jemal A. Global cancer statistics 2018: GLOBOCAN estimates of incidence and mortality worldwide for 36 cancers in 185 countries. CA Cancer J Clin 2018; 68: 394-424.

[2] Chen $\mathrm{W}$, Zheng R, Baade PD, Zhang S, Zeng H, Bray F, Jemal A, Yu XQ and He J. Cancer statistics in China, 2015. CA Cancer J Clin 2016; 66: 115-132.

[3] Gumireddy K, Li A, Gimotty PA, Klein-Szanto AJ, Showe LC, Katsaros D, Coukos G, Zhang L and Huang Q. KLF17 is a negative regulator of epithelial-mesenchymal transition and metastasis in breast cancer. Nat Cell Biol 2009; 11: 1297-1304.

[4] Haber DA, Buckler AJ, Glaser T, Call KM, Pelletier J, Sohn RL, Douglass EC and Housman DE. An internal deletion within an 11p13 zinc finger gene contributes to the development of Wilms' tumor. Cell 1990; 61: 1257-1269.

[5] Scharnhorst V, van der Eb AJ and Jochemsen AG. WT1 proteins: functions in growth and differentiation. Gene 2001; 273: 141-161.

[6] Makrigiannakis A, Coukos G, Mantani A, Prokopakis P, Trew G, Margara R, Winston R and White J. Expression of Wilms' tumor suppressor gene (WT1) in human endometrium: regulation through decidual differentiation. J Clin Endocrinol Metab 2001; 86: 5964-5972.

[7] Wagner KD, Wagner N, Vidal VP, Schley G, Wilhelm D, Schedl A, Englert C and Scholz $\mathrm{H}$. The Wilms' tumor gene Wt1 is required for normal development of the retina. EMBO J 2002; 21: 1398-1405.

[8] Duim SN, Goumans MJ and Kruithof BPT. WT1 in Cardiac Development and Disease. In: van den Heuvel-Eibrink MM, editors. Wilms Tumor. Brisbane (AU): 2016.

[9] Herzer U, Crocoll A, Barton D, Howells N and Englert C. The Wilms tumor suppressor gene wt1 is required for development of the spleen. Curr Biol 1999; 9: 837-840.
[10] Loeb DM and Sukumar S. The role of WT1 in oncogenesis: tumor suppressor or oncogene? Int J Hematol 2002; 76: 117-126.

[11] Yang L, Han Y, Suarez Saiz F and Minden MD. A tumor suppressor and oncogene: the WT1 story. Leukemia 2007; 21: 868-876.

[12] Little M and Wells C. A clinical overview of WT1 gene mutations. Hum Mutat 1997; 9: 209-225.

[13] Stoll R, Lee BM, Debler EW, Laity JH, Wilson IA, Dyson HJ and Wright PE. Structure of the Wilms tumor suppressor protein zinc finger domain bound to DNA. J Mol Biol 2007; 372: 1227-1245.

[14] Oji Y, Ogawa H, Tamaki H, Oka Y, Tsuboi A, Kim EH, Soma T, Tatekawa T, Kawakami M, Asada M, Kishimoto T and Sugiyama H. Expression of the Wilms' tumor gene WT1 in solid tumors and its involvement in tumor cell growth. Jpn J Cancer Res 1999; 90: 194-204.

[15] Ullmark T, Järvstråt L, Sandén C, Montano G, Jernmark-Nilsson H, Lilljebjörn H, Lennartsson A, Fioretos T, Drott K, Vidovic K, Nilsson B, Gullberg U. Distinct global binding patterns of the Wilms tumor gene 1 (WT1) -KTS and +KTS isoforms in leukemic cells. Haematologica 2017; 102: 336-345.

[16] Sugiyama H. WT1 (Wilms' tumor gene 1): biology and cancer immunotherapy. Jpn J Clin Oncol 2010; 40: 377-387.

[17] Huff V. Wilms' tumours: about tumour suppressor genes, an oncogene and a chameleon gene. Nat Rev Cancer 2011; 11: 111-121.

[18] [Internet] http://www.ncbi.nlm.nih.gov/gene/7490.

[19] Hylander B, Repasky E, Shrikant P, Intengan M, Beck A, Driscoll D, Singhal P, Lele $S$ and Odunsi K. Expression of Wilms tumor gene (WT1) in epithelial ovarian cancer. Gynecol Oncol 2006; 101: 12-17.

[20] Fraizer GC, Wu YJ, Hewitt SM, Maity T, Ton CC, Huff V and Saunders GF. Transcriptional regulation of the human Wilms' tumor gene (WT1). Cell type-specific enhancer and promiscuous promoter. J Biol Chem 1994; 269: 8892-8900.

[21] Martinez-Estrada OM, Lettice LA, Essafi A, Guadix JA, Slight J, Velecela V, Hall E, Reichmann J, Devenney PS, Hohenstein P, Hosen N, Hill RE, Munoz-Chapuli R and Hastie ND. Wt1 is required for cardiovascular progenitor cell formation through transcriptional control of Snail and E-cadherin. Nat Genet 2010; 42: 89-93.

[22] Kirschner KM, Sciesielski LK and Scholz H. Wilms' tumour protein Wt1 stimulates transcription of the gene encoding vascular endothelial cadherin. Pflugers Arch 2010; 460: 1051-1061.

[23] Hartkamp J, Carpenter B and Roberts SG. The Wilms' tumor suppressor protein WT1 is processed by the serine protease HtrA2/Omi. Mol Cell 2010; 37: 159-171.

[24] Bandopadhayay P, Jabbour AM, Riffkin C, Salmanidis M, Gordon L, Popovski D, Rigby L, Ashley DM, Watkins DN, Thomas DM, Algar E and Ekert PG. The oncogenic properties of EWS/WT1 of desmoplastic small round cell tumors are unmasked by loss of p53 in murine embryonic fibroblasts. BMC Cancer 2013; 13: 585.

[25] Vicent S, Chen R, Sayles LC, Lin C, Walker RG, Gillespie AK, Subramanian A, Hinkle G, Yang X, Saif S, Root DE, Huff V, Hahn WC and Sweet-Cordero EA. Wilms tumor 1 (WT1) regulates KRAS-driven oncogenesis and senescence in mouse and human models. J Clin Invest 2010; 120: 3940-3952.

[26] Dudnakova T, Spraggon L, Slight J and Hastie N. Actin: a novel interaction partner of WT1 influencing its cell dynamic properties. Oncogene 2010; 29: 1085-1092.

[27] Silberstein GB, Van Horn K, Strickland P, Roberts CT, Jr. and Daniel CW. Altered expression of the WT1 wilms tumor suppressor gene in human breast cancer. Proc Natl Acad Sci U S A 1997; 94: 8132-8137.

[28] Loeb DM, Evron E, Patel CB, Sharma PM, Niranjan B, Buluwela L, Weitzman SA, Korz D and Sukumar S. Wilms' tumor suppressor gene (WT1) is expressed in primary breast tumors despite tumor-specific promoter methylation. Cancer Res 2001; 61: 921-925.

[29] Oji Y, Miyoshi Y, Kiyotoh E, Koga S, Nakano Y, Ando A, Hosen N, Tsuboi A, Kawakami M, Ikegame K, Oka Y, Ogawa H, Noguchi S and Sugiyama H. Absence of mutations in the Wilms' tumor gene WT1 in primary breast cancer. Jpn J Clin Oncol 2004; 34: 74-77.

[30] Provenzano E, Byrne DJ, Russell PA, Wright GM, Generali D and Fox SB. Differential expression of immunohistochemical markers in primary lung and breast cancers enriched for triple-negative tumours. Histopathology 2016; 68: 367-377.

[31] Craig DW, O'Shaughnessy JA, Kiefer JA, Aldrich J, Sinari S, Moses TM, Wong S, Dinh J, Christoforides A, Blum JL, Aitelli CL, Osborne CR, Izatt T, Kurdoglu A, Baker A, Koeman J, Barbacioru C, Sakarya O, De La Vega FM, Siddiqui A, Hoang L, Billings PR, Salhia B, Tolcher AW, Trent JM, Mousses S, Von Hoff D and Carpten JD. Genome and transcriptome sequencing in prospective metastatic triple-negative breast cancer uncovers therapeutic vulnerabilities. Mol Cancer Ther 2013; 12: 104-116.

[32] Qi XW, Zheng XD, Zong BG, Chen QQ, Zhang F, Yang XH, Zhang Y, Liu JL and Jiang J. Association between WT1 polymorphisms and susceptibility to breast cancer: results from a case-control study in a southwestern Chinese population. Am J Cancer Res 2015; 5: 1234-1250.

[33] McGregor RJ, Chau YY, Kendall TJ, Artibani M, Hastie N and Hadoke PWF. WT1 expression in vessels varies with histopathological grade in tumour-bearing and control tissue from patients with breast cancer. Br J Cancer 2018; 119: 1508-1517.

[34] Miyoshi Y, Ando A, Egawa C, Taguchi T, Tamaki Y, Tamaki H, Sugiyama H and Noguchi S. High expression of Wilms' tumor suppressor gene predicts poor prognosis in breast cancer patients. Clin Cancer Res 2002; 8: 1167-1171. 
[35] Qi XW, Zhang F, Yang XH, Fan LJ, Zhang Y, Liang Y, Ren L, Zhong L, Chen QQ, Zhang KY, Zang WD, Wang LS, Zhang Y and Jiang J. High Wilms' tumor 1 mRNA expression correlates with basal-like and ERBB2 molecular subtypes and poor prognosis of breast cancer. Oncol Rep 2012; 28: 1231-1236.

[36] Choi EJ, Yun JA, Jeon EK, Won HS, Ko YH and Kim SY. Prognostic significance of RSPO1, WNT1, P16, WT1, and SDC1 expressions in invasive ductal carcinoma of the breast. World J Surg Oncol 2013; 11: 314

[37] Qi XW, Zhang F, Wu H, Liu JL, Zong BG, Xu C and Jiang J. Wilms' tumor 1 (WT1) expression and prognosis in solid cancer patients: a systematic review and meta-analysis. Sci Rep 2015; 5: 8924

[38] Higgins M, Curigliano G, Dieras V, Kuemmel S, Kunz G, Fasching PA, Campone M, Bachelot T, Krivorotko P, Chan S, Ferro A, Schwartzberg L, Gillet M, De Sousa Alves PM, Wascotte V, Lehmann FF and Goss P. Safety and immunogenicity of neoadjuvant treatment using WT1-immunotherapeutic in combination with standard therapy in patients with WT1-positive Stage II/III breast cancer: a randomized Phase I study. Breast Cancer Res Treat 2017; 162: 479-488.

[39] Zhang W, Lu X, Cui P, Piao C, Xiao M, Liu X, Wang Y, Wu X, Liu J and Yang L. Phase I/II clinical trial of a Wilms' tumor 1-targeted dendritic cell vaccination-based immunotherapy in patients with advanced cancer. Cancer Immunol Immunother 2019; 68: 121-130.

[40] Li MM, Shao YB, Liu H, Xu B and He BX. Effect of single nucleotide polymorphisms of RS1799937 located in WT1 gene on the pathlogical complete response to neoadjuvant chemotherapy in breast cancer patients. Zhonghua Yi Xue Za Zhi 2016; 96: 3559-3562.

[41] Wu L, Yao L, Zhang H, Ouyang T, Li J, Wang T, Fan Z, Fan T, Lin B, Yin CC and Xie Y. A genome-wide association study identifies WT1 variant with better response to 5-fluorouracil, pirarubicin and cyclophosphamide neoadjuvant chemotherapy in breast cancer patients. Oncotarget 2016; 7: 5042-5052.

[42] Zapata-Benavides $\mathrm{P}$, Tuna M, Lopez-Berestein G and Tari AM. Downregulation of Wilms' tumor 1 protein inhibits breast cancer proliferation. Biochem Biophys Res Commun 2002; 295: 784-790.

[43] Caldon CE, Lee CS, Sutherland RL and Musgrove EA. Wilms' tumor protein 1: an early target of progestin regulation in T-47D breast cancer cells that modulates proliferation and differentiation. Oncogene 2008; 27: 126-138.

[44] Nasomyon T, Samphao S, Sangkhathat S, Mahattanobon S and Graidist P. Correlation of Wilms' tumor 1 isoforms with HER2 and ER-alpha and its oncogenic role in breast cancer. Anticancer Res 2014; 34: 1333-1342.

[45] Navakanit R, Graidist P, Leeanansaksiri W and Dechsukum C. Growth inhibition of breast cancer cell line MCF-7 by siRNA silencing of Wilms tumor 1 gene. J Med Assoc Thai 2007; 90: 2416-2421.

[46] Tuna M, Chavez-Reyes A and Tari AM. HER2/neu increases the expression of Wilms' Tumor 1 (WT1) protein to stimulate S-phase proliferation and inhibit apoptosis in breast cancer cells. Oncogene 2005; 24: 1648-1652.

[47] Han Y, Yang L, Suarez-Saiz F, San-Marina S, Cui J and Minden MD. Wilms' tumor 1 suppressor gene mediates antiestrogen resistance via down-regulation of estrogen receptor-alpha expression in breast cancer cells. Mol Cancer Res 2008; 6: 1347-1355.

[48] Wang L, Zhang X and Wang ZY. The Wilms' tumor suppressor WT1 regulates expression of members of the epidermal growth factor receptor (EGFR) and estrogen receptor in acquired tamoxifen resistance. Anticancer Res 2010; 30: 3637-3642.

[49] Loeb DM. WT1 influences apoptosis through transcriptional regulation of Bcl-2 family members. Cell Cycle 2006; 5: 1249-1253.

[50] Graidist P, Nawakhanitworakul R, Saekoo J, Dechsukhum C and Fujise K. Anti-apoptotic function of T-KTS+, T-KTS-, WT1+/+ and WT1+/- isoforms in breast cancer. Asian Biomedicine 2010; 4: 711-720.

[51] Zhang TF, Yu SQ, Guan LS and Wang ZY. Inhibition of breast cancer cell growth by the Wilms' tumor suppressor WT1 is associated with a destabilization of beta-catenin. Anticancer Res 2003; 23: 3575-3584.

[52] Reizner N, Maor S, Sarfstein R, Abramovitch S, Welshons WV, Curran EM, Lee AV and Werner H. The WT1 Wilms' tumor suppressor gene product interacts with estrogen receptor-alpha and regulates IGF-I receptor gene transcription in breast cancer cells. J Mol Endocrinol 2005; 35: 135-144.

[53] Wang L and Wang ZY. The Wilms' tumor suppressor WT1 inhibits malignant progression of neoplastigenic mammary epithelial cells. Anticancer Res 2008; 28: 2155-2160

[54] Burwell EA, McCarty GP, Simpson LA, Thompson KA and Loeb DM. Isoforms of Wilms' tumor suppressor gene (WT1) have distinct effects on mammary epithelial cells. Oncogene 2007; 26: 3423-3430.

[55] Jomgeow T, Oji Y, Tsuji N, Ikeda Y, Ito K, Tsuda A, Nakazawa T, Tatsumi N, Sakaguchi N, Takashima S, Shirakata T, Nishida S, Hosen N, Kawakami M, Tsuboi A, Oka Y, Itoh K and Sugiyama H. Wilms' tumor gene WT1 17AA(-)/KTS(-) isoform induces morphological changes and promotes cell migration and invasion in vitro. Cancer Sci 2006; 97: 259-270.

[56] Lee KY, Jeon YJ, Kim HG, Ryu J, Lim DY, Jung SK, Yu DH, Chen H, Bode AM and Dong Z. The CUG-translated WT1, not AUG-WT1, is an oncogene. Carcinogenesis 2017; 38: 1228-1240.

[57] Zang XP, Pento JT and Tari AM. Wilms' tumor 1 protein and focal adhesion kinase mediate keratinocyte growth factor signaling in breast cancer cells. Anticancer Res 2008; 28: 133-137.

[58] Artibani M, Sims AH, Slight J, Aitken S, Thornburn A, Muir M, Brunton VG, Del-Pozo J, Morrison LR, Katz E, Hastie ND and Hohenstein P. WT1 expression in breast cancer disrupts the epithelial/mesenchymal balance of tumour cells and correlates with the metabolic response to docetaxel. Sci Rep 2017; 7: 45255 .

[59] Bissanum R, Lirdprapamongkol K, Svasti J, Navakanitworakul R and Kanokwiroon K. The role of WT1 isoforms in vasculogenic mimicry and metastatic potential of human triple negative breast cancer cells. Biochem Biophys Res Commun 2017; 494: 256-262.

[60] Qi XW, Yang XH, Fan LJ, Zhang Y, Zhang F and Jiang J. WT1 promotes the proliferation, invasion and migration of breast cancer cells through regulating Id1. Eur J Cancer 2013; 49: S3-S4.

[61] Dong L, Pietsch S, Tan Z, Perner B, Sierig R, Kruspe D, Groth M, Witzgall R, Gröne HJ, Platzer M, Englert C. Integration of Cistromic and Transcriptomic Analyses Identifies Nphs2, Mafb, and Magi2 as Wilms' Tumor 1 Target Genes in Podocyte Differentiation and Maintenance. J Am Soc Nephrol 2015; 26: 2118-2128.

[62] Chesor M, Roytrakul S, Graidist P and Kanokwiroon K. Proteomics analysis of siRNA-mediated silencing of Wilms' tumor 1 in the MDA-MB-468 breast cancer cell line. Oncol Rep 2014; 31: 1754-1760.

[63] Keating GL, Reid HM, Eivers SB, Mulvaney EP and Kinsella BT. Transcriptional regulation of the human thromboxane A2 receptor gene by Wilms' tumor (WT) 1 and hypermethylated in cancer (HIC) 1 in prostate and breast cancers. Biochim Biophys Acta 2014; 1839: 476-492.

[64] Tuna $\mathrm{M}$ and Itamochi $\mathrm{H}$. Insulin-like growth factor I regulates the expression of isoforms of Wilms' tumor 1 gene in breast cancer. Tumori 2013; 99: 715-722.

[65] Xie F, Hosany S, Zhong S, Jiang Y, Zhang F, Lin L, Wang X, Gao S and Hu X. MicroRNA-193a inhibits breast cancer proliferation and metastasis by downregulating WT1. PLoS One 2017; 12: e0185565.

[66] Cheng H, Wang S and Feng R. STIM1 plays an important role in TGF-beta-induced suppression of breast cancer cell proliferation. Oncotarget 2016; 7: 16866-16878 